\title{
UM PANORAMA DA PESQUISA NA FORMAÇÃO CONTINUADA EM EDUCAÇÃO AMBIENTAL NO VALE DO ITAJAÍ-SC: UM OLHAR DO GEEAS-UNIVALI
}

\author{
Antonio Fernando Silveira Guerra ${ }^{1}$, Mara Lúcia Figueiredo ${ }^{2}$, Yara Christina \\ Cesário Pereira ${ }^{3}$, Raquel Fabiane Mafra Orsi ${ }^{4}$, Cleusa Hubner Kazmierczak ${ }^{5}$
}

Resumo: $\mathrm{O}$ artigo apresenta a trajetória de pesquisa desenvolvida durante processos de formação continuada em Educação Ambiental do Grupo de Pesquisa Educação, Estudos Ambientais e Sociedade (GEEAS), do Programa de Mestrado em Educação da Univali, Itajaí, Santa Catarina.

Palavras-chave: educação ambiental, formação continuada, GEEAS.

Abstract: This article presents the trajectory of a research developed during processes of continuing education in Environmental Education by the Education, Environmental Studies and Society Research Group (GREES), of the Graduate Program in Education of Univali, Itajaí, Santa Catarina.

Keywords: environmental education, continuing education, GEEAS.

\section{Introdução}

Este artigo apresenta a trajetória de pesquisa e intervenção na inserção da dimensão ambiental nos processos de formação continuada em Educação Ambiental do Grupo de Pesquisa Educação, Estudos Ambientais e Sociedade (GEEAS), vinculado ao Programa de Pós-Graduação Mestrado Acadêmico em Educação - PPGE, da Universidade do Vale do Itajaí - Univali, em Santa Catarina.

\footnotetext{
${ }^{1}$ Professor, líder e pesquisador do GEEAS/Univali

${ }^{2}$ Centro Universitário de Brusque - Unifebe

${ }^{3}$ Professora e pesquisadora do GEEAS/Univali

${ }^{4}$ Articuladora de EA da Gerência de Educação/GERED-Itajaí

${ }^{5}$ Professora da rede pública municipal de Balneário Camboriú
} 
O GEEAS é cadastrado no Diretório dos Grupos de Pesquisa do CNPq. Adota como foco de pesquisa a formação de educadores ambientais e reúne pesquisadores e mestrandos do PPGE - UNIVALI, professores das redes pública e privada de ensino, gestores e técnicos de Secretarias Municipais de Educação e Fundações de Meio Ambiente da região da Associação de Municípios da Foz do Rio Itajaí (AMFRI), no litoral centro-norte de Santa Catarina, que, juntos, buscam no diálogo e interação com a universidade o conhecimento para o aperfeiçoamento de suas práticas. Até 2007, seu coordenador foi o Prof. José Erno Taglieber. Desde então, é coordenado pelo Prof. Antonio Fernando Silveira Guerra.

O GEEAS iniciou seu processo de formação em agosto de 2000, integrando pesquisa, ensino e extensão por meio de estudos sobre os fundamentos e práticas em EA associados a processos-projetos de intervenção na formação continuada em EA. Nos primeiros anos de trabalho realizou junto a professores da rede pública da Região da AMFRI, o diagnóstico de representações de meio ambiente e de percepção da problemática socioambiental na região. A ênfase dos trabalhos foi confrontar os professores com o contraste entre a beleza cênica da região e os problemas socioambientais produzidos pelos conflitos de interesse econômico, ocupação irregular, falta de saneamento básico, dentre outros, discutindo com os educadores os limites e as possibilidades de seu enfrentamento envolvendo ações e projetos que promovam a inserção da dimensão ambiental nos Projetos Político- Pedagógicos (PPP) das escolas e nas práticas de grupos sociais na micro-região.

\section{Linhas de pesquisa e projetos executados}

Em 2001, o GEEAS ofereceu seu primeiro Seminário no PPGE da Univali, "A Dimensão Ambiental no currículo do ensino fundamental e médio". A questão de pesquisa do grupo no Seminário foi discutir a crise de paradigmas e abordagem das questões ambientais nas diferentes dimensões: ecológica, histórica, política e ética, com base em Cascino (2000), Diegues (1998) e Reigota $(1995,1999)$. Para fundamentar o processo de inserção da "dimensão ambiental" no currículo, Sato (2000, 2001), Guimarães (1995), Guerra (2001), dentre outros, foram importantes referenciais.

O Seminário foi encerrado com uma palestra de Michéle Sato sobre "As tendências nas pesquisas em Educação Ambiental". O encontro do grupo com esta pesquisadora se deu por conta de uma afinidade epistemológica e um reconhecimento mútuo das ideias e valores em relação à EA. Isto permitiu a construção de uma identidade de Grupo, ampliando o acesso e a discussão sobre os referenciais teóricos e objetivos em EA, necessários para que o grupo pudesse 
traçar as coordenadas que orientassem sua trajetória na pesquisa e formação em $\mathrm{EA}^{6}$.

\subsection{A linha de pesquisa e intervenção nos processos de formação docente em Educação Ambiental}

$\mathrm{Na}$ linha de pesquisa de formação continuada, o primeiro projeto do GEEAS foi desenvolvido em 2000 com quarenta professores de Ciências e Biologia e denominado "Uma experiência de formação de professores de biologia com ênfase na Educação Ambiental”, financiado pela FUNCITEC, hoje FAPESC,

No período de 2002 a 2004 o GEEAS, tomando como fundamento os trabalhos sobre as representações sociais (MOSCOVICI, 2003) de meio ambiente, especialmente as categorias sugeridas por Reigota (1995), e trabalhos de Alves-Mazzotti (2000) e Ruscheinsky (2002), desenvolveu o Projeto "Educ $\boldsymbol{A} d o$ - Educação Ambiental em áreas costeiras usando a WEB como suporte”. Este projeto realizou levantamento dessas representações e uma intervenção pedagógica junto a 15 professores(as) de três escolas públicas da região. A partir deste estudo tomou-se como subsídio para análise as sete categorias complementares propostas por Sauvé et al. (1996, adaptado por SATO, 2003).

O Projeto "Diagnóstico da Educação e percepção ambiental nas práticas educativas dos docentes da região litorânea - mesorregião do Vale do Itajai" (FUNCITEC - 2002 2003) envolveu sete municípios da AMFRI. Este diagnóstico identificou as representações sobre meio ambiente, EA e percepção da problemática ambiental local e regional de 134 professores de 50 escolas. Os dados, mais uma vez, revelaram representações naturalistas de meio ambiente. Algumas contradições nas práticas educativas confirmaram as constatações dos referenciais teóricos adotados pelo grupo, em que as atividades de EA, na maioria das escolas, seguiam uma "pedagogia tradicional", realizadas de modo pontual e de forma fragmentada, com pequeno envolvimento comunitário, o que Guimarães (2004) chama de uma "fragilização nas práticas de EA" no sentido da formação crítica dos educadores ambientais.

\footnotetext{
${ }^{6} \mathrm{Na}$ época o GEEAS definiu três linhas de pesquisa, que se complementavam: a) EA no currículo - com foco no estudo das percepções e representações de professores e alunos; b) Formação docente inicial e continuada - oferecida em cursos de atualização e de aperfeiçoamento para professores da região e c) Avaliação e produção de materiais e tecnologias para EA - visando o apoio pedagógico nas atividades de inserção da dimensão ambiental no currículo escolar. Em 2008, as linhas foram redefinidas em função das mudanças curriculares do Mestrado em Educação da Univali, para as seguintes: a) Práticas docentes: processos de ensino e aprendizagem; b) Políticas públicas para Educação Ambiental e, c) Materiais e tecnologias para Educação Ambiental.
} 
A referida pesquisa gerou subsídios para duas dissertações de mestrado do PPGE/Univali (LIMA, 20037: ROCHA, 2003²). Os resultados destas dissertações sugeriram um indício de evolução das representações dos professores para uma percepção mais sistêmica das relações ser humano $\Leftrightarrow$ sociedade $\Leftrightarrow$ natureza, se comparados com os resultados da pesquisa-ação realizada por Guerra (2001). Ao mesmo tempo, revelaram que educandos e educadores não percebiam o crescimento e a ocupação das áreas costeiras, onde viviam, como problema ambiental, apenas as suas consequências, como a deposição de resíduos sólidos (lixo) nas praias e da poluição dos principais rios da região (Itajaí-Açú e Camboriú).

Em 2003 o Curso de Atualização em Fundamentos da EA realizado com 35 professores da rede municipal de Piçarras, Navegantes, Itajaí e Balneário Camboriú teve por objetivo, planejar estratégias para o diagnóstico de problemas ambientais e promover o planejamento e execução de projetos de intervenção nas escolas para inserção da dimensão ambiental nas práticas docentes. Os resultados corroboraram a estratégia metodológica adotada pelo Grupo ao trabalhar na formação com os três domínios indicados por Robotton e Hart (1993) e Fien e Tilbury (2002) - Educação SOBRE o ambiente - domínio cognitivo; educação NO ambiente - domínio afetivo; e Educação PARA o ambiente - domínio participativo -, entendidos como complementares entre si (SAUVÈ, 1997).

Os resultados dessas pesquisas, apresentados no Grupo de Trabalho de EA - GT 22 da ANPEd (GUERRA \& TAGLIEBER, 2003), confirmaram que a construção da identidade do educador(a) ambiental não pode se limitar apenas à transmissão de conceitos ecológicos sobre os ecossistemas. Mas, como "sujeito ecológico" (CARVALHO, 2004), ele(a) precisa agir crítica e efetivamente na realidade ambiental, refletindo e buscando entender, na práxis, a complexidade das causas e das inter-relações que levam ao agravamento dos problemas políticos, socioambientais, culturais, históricos e econômicos.

Dois outros projetos de pesquisa e intervenção, envolvendo 90 docentes de 29 escolas municipais, dez estaduais e uma escola da rede privada foram

\footnotetext{
${ }^{7}$ LIMA, M. B. A inserção da dimensão ambiental no currículo: analisando a trajetória de uma comunidade de aprendizagem cooperativa. Itajá, 2003. Dissertação (Mestrado em Educação), Univali.; ROCHA, M. T. A Percepção da Dimensão Ambiental em ação: A caminhada de um grupo no Ensino Fundamental. Itajaí, 2003. Dissertação (Mestrado em Educação), Univali.
} 
realizados ${ }^{9}$. Neles foram investigadas as formas de interpretação da problemática ambiental, a cooperação e autonomia dos grupos formados e as tendências para implantação da EA no PPP das escolas. Essas pesquisas geraram um Trabalho de Conclusão de Curso de Graduação em Biologia e duas dissertações de Mestrado (GAZZONI, 200610; MENGHINI, 200511).

Ainda que o desenvolvimento dos projetos de intervenção nas escolas com envolvimento das comunidades tenha sido muito significativo, a observação participante e a análise dos relatos dos professores(as), que participaram desses projetos, revelou uma série de obstáculos à inserção da dimensão ambiental no currículo escolar. Dentre eles: a) a instabilidade profissional (rotatividade de professores nas escolas); b) a falta de conhecimento, habilidades na área da informática e acesso ao computador e a Internet, fundamentais no processo, pois as atividades estavam inseridas no ambiente virtual de aprendizagem (AVA) do TelEduc da UNIVALI; c) as atividades só tiveram efetividade nas escolas em que a direção e/ou supervisão educacional deram apoio, ou onde houve a formação de um núcleo com lideranças fortes, formado por professores e alunos comprometidos; d) os professores demonstraram que não conheciam ou tinham acesso a materiais pedagógicos para o trabalho em sala para inserir a dimensão ambiental nas suas atividades de sala de aula (TAGLIEBER \& GUERRA, 2006).

No entanto, no início dos projetos as atividades desenvolvidas nas escolas da região, na sua grande maioria, estavam relacionadas com a gestão do lixo na escola: coleta seletiva, reciclagem e redução. Porém, ao final, a variedade de temas foi sensivelmente ampliada pelos participantes. Discutiu-se o consumismo, a ambientalização dos espaços escolares, o bem estar na sala de aula, o aproveitamento das hortas escolares, a preservação dos córregos e das matas ciliares no entorno das escolas, a conservação do solo, entre outros. Percebeu-se não só a aquisição de conhecimentos ecológicos, mas a compreensão da complexidade das inter-relações entre seres humanos, sociedade e natureza e seu conflitos.

9 "Formação de Educadores Ambientais na micro-região da AMFRI/SC - $\left(5^{\mathrm{a}}\right.$ a $8^{\mathrm{a}}$ séries do Ensino Fundamental) - (CNPq - 2003-2005)" e "A problemática da formação docente continuada para Educação Ambiental - Educação Infantil e séries iniciais do Ensino Fundamental" - (FAPESC - 2004-2005);

${ }^{10}$ GAZZONI, C. R. Um estudo o processo de formação continuada de educadores para inserção da dimensão ambiental nas práticas pedagógicas do ensino fundamental. Itajaí, 2006. Dissertação (Mestrado em Educação), Universidade do Vale do Itajaí.

${ }^{11}$ MENGHINI, F. As trilhas interpretativas como recurso pedagógico: Caminhos traçados para a Educação Ambiental. Itajaí, 2005. 119fls. Dissertação (Mestrado em Educação), Universidade do Vale do Itajaí. 


\subsection{Pesquisas em políticas públicas para Educação Ambiental}

$\mathrm{Na}$ linha de Políticas Públicas em EA do GEEAS, o projeto interinstitucional "Tecendo Redes de educação ambiental na Região Sul"12, desenvolvido de 2002 a 2004, resultou no diagnóstico da EA na Região Sul e consolidou o processo de organização da Rede Sul Brasileira de EA - REASul (www.reasul.org.br).

Nos anos de 2003 a 2005, o trabalho de dissertação de Justen ${ }^{13}$ (2005), discutiu a trajetória de atuação de um grupo de professores e técnicos ambientais no Estado do Paraná, no processo de formação de educadores ambientais.

Em 2008, o Grupo produziu o Caderno Pedagógico de EA do município de Itapema (SC) e o trabalho de dissertação de Orsi ${ }^{14}$ (2008) gerou subsídios para análise da ação estruturante do Programa Vamos Cuidar do Brasil com as Escolas (PVCBE), desenvolvido na região da AMFRI. As dissertações de Silva ${ }^{15}$ (2007) e Mafra ${ }^{16}$ (2010) analisaram as aprendizagens dos professores e as políticas públicas de formação no município de Navegantes e, em 2011, o processo de formação continuada no município de Itaiópolis-SC foi estudo por Kazmierczak (2011) ${ }^{17}$.

\subsection{A formação em tecnologias}

12 "Tecendo Redes de educação ambiental na Região Sul” - projeto financiado pelo MMA/ FNMA (2002-2004), envolvendo a UNIVALI e a FURG; duas unidades do IBAMA - CEPSul- Itajaí e NEA-IBAMA - Florianópolis (SC) e uma OSCIP de Curitiba (PR), o Mater Natura - Instituto de Estudos Ambientais.

13 JUSTEN, L. M. Trajetórias de um grupo interinstitucional de um programa de formação de educadores ambientais no Estado do Paraná (1997 - 2002). Itajaí, 2005. Dissertação (Mestrado em Educação), Universidade do Vale do Itajaí.

14 ORSI, R. F. M. A formação continuada do Programa "Vamos Cuidar do Brasil nas escolas" na região da AMFRI, em Santa Catarina. Itajaí, 2008. 116fls. Dissertação (Mestrado em Educação), Universidade do Vale do Itajaí.

15 SILVA. A. M. A inserção da dimensão ambiental dentro do contexto escolar em função da Pedra da Miraguaia. Itajaí : 2007a. 80 fls. Dissertação (Mestrado em Educação), Universidade do Vale do Itajaí

16 MAFRA, A. A formação em educação ambiental no município de Navegantes SC: entre o desejável e o possível. Itajaí, 2010. Dissertação (Mestrado em Educação), Universidade do Vale do Itajaí.

${ }^{17}$ KAZMIERCZAK, C. H. O impacto da formação de professores (as) em Educação Ambiental na rede de ensino de Itaiópolis-SC entre 2007-2008. Itajaí, 2011. Dissertação (Mestrado em Educação), Universidade do Vale do Itajaí. 
$\mathrm{Na}$ terceira linha de pesquisa, a de materiais e tecnologias para EA, em sua dissertação Xavier $(2008)^{18}$ verificou as possibilidades pedagógicas do material denominado "Desenho Animado Ambiental (DAA)19" e de seus temas como estratégia metodológica para EA. Segalla $(2008)^{20}$ apresentou reflexões sobre as possibilidades didático-pedagógicas da revista em quadrinhos "Legislinho para o desenvolvimento de valores e atitudes em prol da conservação e preservação dos manguezais, no município de Itapema (SC).

De 2007 a 2009, o GEEAS executou o Projeto "Desenvolvimento de materiais e tecnologias para Educação Ambiental em escolas da micro-região da foz do rio Itajai" (FAPESC - 2007 - 2008), com 28 professores de diferentes áreas/disciplinas do Ensino Fundamental, para inserção da dimensão ambiental e do uso das tecnologias na prática docente de professores que trabalham com ações e projetos em EA e para aqueles que atuam em laboratórios de informática da rede pública de ensino. As atividades realizadas resultaram na edição do CD ROM multimídia "Educação Ambiental e sustentabilidade: atividades e materiais pedagógicos ${ }^{21 "}$ (GUERRA et al. 2008).

\subsection{Educação Ambiental para a Sustentabilidade}

Desde 2009, a sustentabilidade, suas dimensões e complexidade é objeto de pesquisa do GEEAS no Projeto "O cenário da Educação Ambiental em municípios da região da foz da bacia do Rio Itajaí-SC: Sustentabilidade Socioambiental ou Desenvolvimento Sustentável?” (2009 - 2011), aprovado no Edital Universal MCT/CNPq 02/2009. Esta pesquisa tem como objetivos investigar a ambiguidade dos conceitos e as concepções de Sustentabilidade e Desenvolvimento Sustentável, bem como as abordagens nas práticas pedagógicas e sociais de um grupo de educadores e gestores de órgãos públicos, especialmente em municípios da região da AMFRI, atingidos pelo desastre

18 XAVIER, F. P. Uso do desenho animado ambiental como estratégia metodológica para educação ambiental. Itajaí, 2008. 135 fls. (Mestrado em Educação). Universidade do Vale do Itajaí.

19 O DAA desenvolvido pelo autor é uma mídia em DVD que tem como personagem principal o "menino caranguejo" - Disponível em http://www.caranguejo.com.

20 SEGALLA, M. B. Legislinho e sua turma no manguezal em sala de aula: Contribuições para a Educação Ambiental. Itajaí, 2008. Dissertação (Mestrado em Educação). Universidade do Vale do Itajaí.

${ }^{21}$ Este CD foi organizado em categorias: Introdução, Práticas educativas em EA, Jogos, Banners, Blogs, Slides, Vídeos, Dissertações, Leituras, Sites e Bibliotecas Virtuais, Galeria de Fotos, Manuais. O conteúdo vem sendo trabalhado em escolas municipais e estaduais. 
ambiental de Santa Catarina, em novembro de 2008. O projeto serviu de base para a produção de duas dissertações ${ }^{22}$ no PPGE Univali.

$\mathrm{Na}$ análise parcial dos dados, desse projeto, utilizou-se como referenciais Freitas (2007), Foladori (2007), Floriani (2008), Jacobi, (2003), dentre outros. Até o momento, os resultados do projeto indicam que as questões relacionadas à sustentabilidade social, cultural e política, parecem, ainda, não terem sido devidamente incorporadas às práticas pedagógicas dos 28 professores e nove gestores educacionais, participantes do projeto. Esta conclusão decorre das respostas, ao questionário, focarem na sustentabilidade ecológica (preservação dos recursos).

Percebeu-se também, nos relatos dos participantes da pesquisa, não haver ainda um consenso nos discursos sobre o termo sustentabilidade. Pelo contrário, foi observado grande diversidade de respostas. Quanto ao nível de abordagem, a sustentabilidade vem sendo trabalhada de maneira efetiva pelos professores(as) em suas práticas cotidianas, mas a aula expositiva ainda é a principal estratégia utilizada, embora os temas ambientais estejam presentes nas atividades pedagógicas, ainda que de maneira a tratar a EA mais fortemente do ponto de vista da sustentabilidade ecológica, ou seja, da visão tradicional da EA direcionada à conservação e preservação de recursos naturais.

Como uma das metas desse projeto, o grupo iniciou em 2010 a organização e validação do material do segundo volume do CD ROM multimídia "Educação Ambiental e sustentabilidade: atividades e materiais pedagógicos", com o tema Educação Ambiental: As Dimensões da Sustentabilidade (GUERRA e FIGUEIREDO, 2011).

\subsection{Organização de eventos e publicações do grupo}

Para socializar os trabalhos realizados, o GEEAS produziu publicações em EA, em parceira com outros pesquisadores nacionais. Publicou, em 2004, o livro "Pesquisa em Educação Ambiental: Pensamentos e reflexões de pesquisadores em Educação Ambiental” (TAGLIBER \& GUERRA, 2004) e, em 2007, o livro "Educaşão Ambiental: Fundamentos, práticas e desafios" (GUERRA \& TAGLIEBER, 2007).

${ }^{22}$ JONER, G. L.. O princípio da responsabilidade como fundamento filosófico da ética ambeintal para a sustentabilidade: contribuições de Hans Jonas. Itajaí, 2010. Dissertação (Mestrado em Educação), Universidade do Vale do Itajaí; ROSA, T. A.D.. Sustentabilidade ou desenvolvimento sustentável: Os debates e embates frente à complexidade dos termos. Itajaí, 2011. Dissertação (Mestrado em Educação), Universidade do Vale do Itajaí. 
Em 2003, a Univali e o Grupo coordenaram o II Simpósio Sul Brasileiro de EA (II SSBEA) e o I Colóquio de Pesquisadores em Educação Ambiental da Região Sul - I CPEASul, em Itajaí. Em 2008, o GEEAS organizou, em parceria com a ULBRA e FURG, o III Colóquio de Pesquisadores em Educação Ambiental da Região Sul - III CPEASul e o volume especial da Revista Eletrônica do Mestrado em Educação Ambiental da FURG ${ }^{23}$, com os artigos apresentados no evento.

Dos debates sobre o tema sustentabilidade no III CPEASul, emergiu o desafio de organizar o livro "Sustentabilidades em diálogos" (GUERRA \& FIGUEIREDO, 2010), lançado durante a realização do IV CPEASul.

Com a coordenação geral do GEEAS, e com a parceria de 13 Programas de Pós-Graduação da região Sul, o IV CPEASul e Encontro da Rede Sul Brasileira de Educação Ambiental - REASul ocorreu de 23 a 25 de setembro de 2010, como parte das comemorações dos 10 anos do Programa de Mestrado Acadêmico em Educação - PPGE, da Univali, Os trabalhos dos Grupos temáticos foram publicados em um número especial da Revista Eletrônica do Mestrado em Educação Ambiental da $\mathrm{FURG}^{24}$ e os resumos expandidos dos trabalhos nos anais do evento.

\section{Refletindo sobre os obstáculos e possibilidades do processo de formação em Educação Ambiental}

A experiência acumulada nos processos de formação, avaliação e autoavaliação junto aos professores e pesquisadores do GEEAS permitiu identificar uma série de obstáculos ao processo de formação em EA. A falta de tempo, a instabilidade profissional e a baixa auto-estima, que leva professores a demonstrar sintomas de estresse profissional conhecidos como Síndrome de Bornout ${ }^{25}$; a fragmentação do conteúdo e atividades pontuais executadas nas escolas e impostas por técnicos e especialistas, que não permitem ao professor(a) imprimir um ritmo adequado às atividades pedagógicas, são alguns dos obstáculos identificados.

Observou-se que as atividades nas escolas são pensadas de forma isolada e estanque, não apresentando um eixo teórico, uma filosofia educacional, que as unifique no processo educativo. No campo teórico, os professores desconhecem

${ }^{23} \mathrm{O}$ número especial está disponível em http://www.remea.furg.br/indvolesp08.php.

${ }^{24} \mathrm{O}$ número especial está disponível em http://www.remea.furg.br/indvolesp2010.php .

25 Definida como uma das consequências mais marcantes do estresse profissional, se caracteriza por exaustão emocional, avaliação negativa de si mesmo, depressão e insensibilidade com relação a quase tudo e todos. Disponível em: www.psiqweb.med.br/cursos/stress4.html. Acesso em 14 nov. 2005. 
conceitos como o da leitura de mundo a partir da complexidade (MORIN, 1996) ou de sociedade de risco (BECK, 199726) e mal ouviram falar na abordagem crítica da EA (LOUREIRO, 2004, 2006, TOZONI, 2007). Estas constatações confirmam a fragilização das práticas educacionais em EA indicadas por Guimarães (2004). Existe a intenção da mudança, da transformação, porém, o que chega ao "chão da escola" é diferente. A transformação esbarra nos obstáculos epistemológicos, pedagógicos e na organização disciplinar da escola.

Os trabalhos de pesquisa e intervenção do GEEAS vêm apontando a necessidade de que as Políticas Públicas em EA invistam efetivamente na formação continuada dos educadores para inserção da dimensão ambiental no currículo, como também a necessidade de informação para que o educador conheça para poder intervir sobre a realidade dos problemas socioambientais. Os caminhos podem ser inúmeros, porém, em comum, têm a busca por uma educação de qualidade, socialmente justa, participativa, solidária e ambientalmente sustentável.

Outra característica marcante do GEEAS, nesses 10 anos, tem sido a formação e participação no grupo de gestores educacionais de municípios da região, tanto no planejamento quanto no acompanhamento nos processos de formação continuada junto às redes de ensino municipais e estadual. Com isto, é possível o acompanhamento sistemático dos professores pelos gestores e pesquisadores do grupo, elaborando subsídios para a organização de cursos, formação de pequenos grupos nas escolas (professores, alunos e pessoas da comunidade), organizados, por exemplo, em Comissões de Meio Ambiente (COMDEMA) e de Qualidade de Vida (COM-VIDA) e na Sala Verde da Univali. Isto estimula discussões sobre a problemática socioambiental e sua inserção nos Projetos Políticos Pedagógicos, bem como a reflexão sobre suas práticas nas escolas e ações coletivas nas comunidades, potencializando os processos de mudança requeridos pela EA (TAGLIEBER \& GUERRA, 2007).

A identidade do GEEAS, sua pesquisa e seus fundamentos foram construídos ao longo destes 10 anos com a contribuição daqueles e daquelas que, com seu conhecimento, atitudes e ações fortaleceram a trajetória do Grupo. Com as discussões apresentadas por Marilia Tozoni-Reis (TOZONI-REIS, 2007) no GT de EA da ANPED, os pesquisadores do GEEAS iniciaram um aprofundamento teórico no estudo dos fundamentos da EA crítica e emancipatória, participando, por exemplo, de um Seminário em Curitiba (PR)

\footnotetext{
${ }^{26}$ Segundo Beck (1997), "Este conceito designa uma fase no desenvolvimento da sociedade moderna, em que os riscos sociais, políticos, econômicos e individuais tendem cada vez mais a escapar das instituições para o controle e a proteção da sociedade industrial” (BECK apud BECK, GIDDENS e LASH, 1997, p. 15).
} 
com Carlos Frederico Loureiro - UFRJ (LOUREIRO, 2004; LOUREIRO et. al, 2006). A pesquisa de Martha Tristão (2004) sobre a formação inicial e continuada também contribuiu com as ações do Grupo. Em 2008, um Seminário sobre Paulo Freire, oferecido no PPGE/UNIVALI por João Figueiredo (UFCE), vicecoordenador do GT 22 da ANPED na época, enriqueceu o trabalho de formação continuada dos professores na perspectiva freireana.

Nesses 10 anos de existência do GEEAS, questões teórico-metodológicas e das políticas educacionais ainda nos inquietam, mas também nos inspiram e desafiam no sentido de enfrentar os limites e possibilidades para tornar realidade o desenvolvimento de uma EA crítica e emancipatória, no sentido da construção de sociedades sustentáveis, mais justas e responsáveis.

\section{Referências}

ALVES-MAZZOTTI, A. J. Representações sociais: desenvolvimentos atuais e aplicações à educação. In: CANDAU, V. M. (Org). Linguagens, espaços e tempos no ensinar e aprender. Encontro Nacional de Didática e Prática de Ensino (ENDIP). DP\&A: Rio de Janeiro, 2000. p. 57-73.

CARVALHO, I. C. de M. Educação ambiental: a formação do sujeito ecológico. São Paulo: Cortez, 2004.

CASCINO, F. Educação Ambiental: princípios, história, formação de professores. 2. ed. São Paulo: SENAC, 2000.

FIEN, J.; TILBURY, D. The global challenge of sustainability. In: TILBURY, D. et. al. (Eds.). Education and sustainability: responding to the global challenge. Gland and Cambridge: CEC/IUCN, 2002. p. 1-12.

FOLADORI, G. Paradojas de la sustentabilidad: ecológica versus social. 2007. Disponível em: <http: // trayectorias.uanl.mx/>. Acesso em: 5 abr. 2010.

FLORIANI, D. Obstáculos e potencialidades para a construção de uma sociedade sustentável, na perspectiva da Educação e da prática sócio-ambientais. In: Rev. eletrônica Mestr. Educ. Ambient., v. especial, dez. de 2008, p. 87-103.

FREITAS, M. A Década da Educação para o Desenvolvimento Sustentável - Do Que não deve ser ao que pode Ser -. In: CONGRESSO IBERO-AMERICANO DE EDUCAÇÃO AMBIENTAL. 5, 2006, Anais... Joinville: Associação Projeto Roda Viva, 2007, p. 125 - 140, 2007.

GUERRA, A. F. S. Diário de bordo: navegando em um ambiente de aprendizagem cooperativa para educação ambiental. Florianópolis, 2001. 336 f. Tese (Doutorado em Engenharia de Produção) - Programa de Pós-Graduação em Engenharia de Produção, UFSC.

GUERRA, A. F. S.; FIGUEIREDO, M. L. (Orgs.) Sustentabilidades em Diálogos. Itajaí: Univali, 2010. 
Educação Ambiental e sustentabilidade: atividades e materiais pedagógicos. Itajaí: Univali/CNPQ, 2011. 1 CD.

GUERRA, A. F. S. et al. Educação Ambiental e sustentabilidade: atividades e materiais pedagógicos. Itajaí: Univali, 2008. 1 CD

GUERRA, A. F. S., TAGLIEBER, J. E. Educação Ambiental: Fundamentos, práticas e desafios. Itajaí - SC: UNIVALI, 2007, v.1.

; ___ A inserção da educação ambiental no currículo: $\mathrm{O}$ olhar dos pesquisadores de um Programa de Mestrado em Educação. REUNIÃO ANUAL DA ANPED. (25., 2003). Anais... Poços de Caldas: ANPED, 2003 (1 CD ROM).

GUIMARÃES, M. A formação de educadores ambientais. Campinas: Papirus, 2004.

. A dimensão ambiental na educação. 3. ed. Campinas: Papirus, 1995.

JACOBI, P. Educação ambiental, cidadania e sustentabilidade. In: Cadernos de Pesquisa. n. 118. São Paulo: Autores Associados, 2003. p. 189-205.

LOUREIRO, C. F. B. Trajetória e fundamentos da educação ambiental. São Paulo: Cortez, 2004.

LAYRARGUES, P. P.; CASTRO, R. S de. Pensamento complexo, dialética e educação ambiental. São Paulo: Cortez, 2006.

MOSCOVICI, S. Representações sociais: investigações em psicologia social. Petrópolis, RJ: Vozes, 2003.

MORIN, E. O problema epistemológico da complexidade. 2. Ed. Portugal: Publicações Europa-América, 1996.

REIGOTA, M. A floresta e a escola: por uma educação ambiental pós-moderna. São Paulo: Cortez, 1999.

. Meio ambiente e representações sociais. São Paulo: Cortez, 1995.

ROBOTTOM, I.; HART, P. Research in environmental education. Victoria: Deakin University, 1993.

RUSCHEINSKY, A. Sociologia das Representações Sociais e a Educação Ambiental. In: SEMINÁRIO DE PESQUISA DA REGIÃO SUL, 4., 2002, Florianópolis. Anais... 4. Florianópolis, UFSC/NUP, v.1, p.16, 2002.

SATO, M. Educação ambiental. São Carlos: Rima, 2003.

. Apaixonadamente pesquisadora em educação ambiental. Educação, Teoria e

Prática, Rio Claro, v. 9, n.16, p. 24-35, jan./jun. 2001.

. Formação em educação ambiental: da escola à comunidade. In: MEC.

Reflexões sobre o Panorama da Educação Ambiental no Ensino Formal. Brasília: COEA, MEC, 28 e 29 fev. 2000.

SAUVÉ, L. La educacion ambiental: hacia un enfoque global y crítico. In: SAUVÉ, L.; BARBA, A. T.; SATO, M.; CASTILLO, E. Y. Actas del Seminário internacional de 
investigación-formación EDAMZ, 1996. Anais... Quebéc: Université du Quebéc à Montreal, 1996. p. 85-104.

TAGLIEBER, J. E.; GUERRA, A. F. S. Formação continuada de professores em Educação Ambiental: contribuições, obstáculos e desafios. In: REUNIÃO ANUAL DA ANPED, 30., 2007, Caxambu. Anais... Rio de Janeiro: ANPED, 2007. p. 1-16. CDROM.

TAglieber, J. E., GUERRA, A. F. S. Pesquisa em Educação Ambiental: Pensamentos e reflexões de pesquisadores em Educação Ambiental. Pelotas : Ed. Universitária/UFPel, 2004.

TOZONI-REIS, M. Contribuições para uma pedagogia crítica na educação ambiental: reflexões teóricas In: REUNIÃO ANUAL DA ANPED, 30., 2007, Caxambu. Anais... Caxambu: ANPED, 2007.

TRISTÃO, M. A educação ambiental na formação de professores: redes de saberes. São Paulo: Annablume; Vitória: Facitec, 2004.

Artigo: recebido em 20/08/2010 _ _ aprovado em 17/12/2010 